\title{
Towards optimal hormonal treatment of male to female gender identity disorder
}

\author{
Rosemary J Basson MB BS MRCP
}

\section{RJ Basson. Towards optimal hormonal treatment of male to female gender identity disorder. J Sex Reprod Med 2001;1(1):45-51.}

Hormonal management of male to female gender identity disorder occurs in the offices of family practitioners, internists and endocrinologists, as well as in established gender dysphoria clinics. Despite detailed and updated standards of care for diagnosis, namely, the Harry Benjamin International Association guidelines, those same guidelines state that "physicians have a wide latitude in what hormone preparation they may prescribe and what routes of administration they may select". Treatment is varied and often includes doses of estrogen that are supraphysiological for biological women, sometimes even higher than those in currently prescribed oral contraceptives. Despite clinical experience and published evidence that thromboembolic phenomena are induced by a high estrogen regimen, the practice continues. Both theoretical arguments and clinical experience support the use of doses of estrogen that would be physiological for a biological woman but, nevertheless, do allow feminization. This is possible because testosterone production is simultaneously suppressed and its action antagonized using progestins and selected antiandrogen medications that lack serious medical side effects. Oral estrogen, medroxyprogesterone and spironolactone are commonly prescribed, but certain variations are demanded by different risk factors. Some of estrogen's most likely cardiovascular protective mechanisms in the biological woman have been shown to apply to the transgendered person, and others have not. Low dose estrogen regimens were used in
279 persons with male to female gender identity disorder who were followed in the author's clinic for periods of up to 12 years. Fewer patients experienced myocardial infarctions, cerebrovascular accidents and thromboembolic events than would be expected in the general male population.

Key Words: Hormonal treatment; Male to female gender identity disorder

\section{Vers un traitement hormonal optimal du trouble de l'identité sexuelle homme-femme}

RÉSUMÉ : Le traitement hormonal du trouble de l'identité sexuelle homme-femme se pratique dans les cabinets des omnipraticiens, des internistes et des endocrinologues, ainsi que dans les cliniques de correction de la dysphorie sexuelle. Malgré des normes de soins détaillées et mises à jour, relatives au diagnostic du trouble, nommément les lignes de conduite de l'Harry Benjamin International Association, ces mêmes lignes de conduite stipulent que les médecins disposent d'une grande latitude en ce qui concerne la préparation hormonale et la voie d'administration. Le traitement prend diverses formes et, souvent, les doses d'oestrogènes sont " supraphysiologiques » pour les femmes biologiques, dépassant même parfois les doses actuelles prescrites pour les contraceptifs oraux. Malgré l'expérience clinique et les données publiées selon lesquelles les traitements composés de fortes doses d'oestrogènes sont cause $d^{\prime}$ 'accidents thrombo-emboliques, la pratique se poursuit. Des arguments théoriques et l'expérience clinique étayent le recours à des doses d'oestrogènes qui s'avèrent physiologiques pour les femmes

voir page suivante 
biologiques, mais qui permettent néanmoins une féminisation. Cela est rendu possible grâce à la suppression concomitante de la production de testostérone et à sa neutralisation par des progestatifs et des antiandrogènes sélectionnés, qui ne produisent pas d'effets indésirables médicaux sérieux. Les médecins prescrivent souvent des oestrogènes oraux, la médroxyprogestérone et la spironolactone, mais ils doivent également tenir compte de différents facteurs de risque. Certains mécanismes de protection cardiovasculaire attribuables aux oestrogènes et observables chez les femmes biologiques sont actifs chez les transgénéristes, mais d'autres ne le sont pas. Des traitements composés de faibles doses d'oestrogènes ont été prescrits à 279 personnes souffrant du trouble de l'identité sexuelle hommefemme, et le suivi à la clinique de l'auteure a duré jusqu'à 12 ans dans certains cas. Résultat : le nombre d'infarctus du myocarde, $\mathrm{d}$ 'accidents vasculaires cérébraux et d'accidents thromboemboliques a été inférieur aux prévisions faites à cet égard pour la population d'hommes en général.
C linicians who treat patients with male to female gender identity disorder (GID) recognize that optimal pharmacological feminization is desirable because some masculine features are irreversible and threaten a person's ability to pass as a woman. Broad shoulders and broad thorax, a more angular jaw, a larger nose and larynx, larger hands and feet, plus a deeper voice remain unchanged with hormonal treatment.

The objectives that guide hormone prescription before sex reassignment surgery (SRS) are as follows:

- suppression of testicular testosterone;

- antagonism of adrenal and testicular testosterone;

- facilitation of endogenous estrogen activity; and

- the addition of estrogen in physiological doses for feminization.

Thus, the patient who seeks SRS primarily requests physical changes (1) and is aware of the likely consequences on sexual function. However, marked metabolic changes that result from increasing estrogen activity and decreasing androgen activity in a person who was previously exposed to high androgen levels, including alterations in lipid, bone, red blood cell and muscle metabolism, often occur. Changes in blood coagulation, insulin sensitivity and blood pressure are possible. With exposure to female levels of estrogen for more than 20 years, the risk of breast cancer may approach that of biological women. In the future, it may be possible to use selective estrogen receptor modulators (SERMS) to allow feminization while avoiding an increase in thrombogenesis. Currently, physicians seek to understand the actions of available estrogens to minimize risks, particularly those related to cardiovascular health.

\section{DRUGS USED IN HORMONAL TREATMENT FOR MALE TO FEMALE GID}

Theoretically, the lack of activity of testosterone and dihydrotestosterone (DHT) can be achieved by the various methods shown in Figure 1. These methods include the suppression of gonadotrophic releasing hormone (GNRH) by using the continuous stimulus of GNRH agonists; the use of GNRH antagonists; the suppression of luteinizing hormone (LH) by using progestins, medroxyprogesterone acetate (MPA), cyproterone acetate (CPA) or micronized progesterone; the inhibition of 5-alpha reductase, limiting

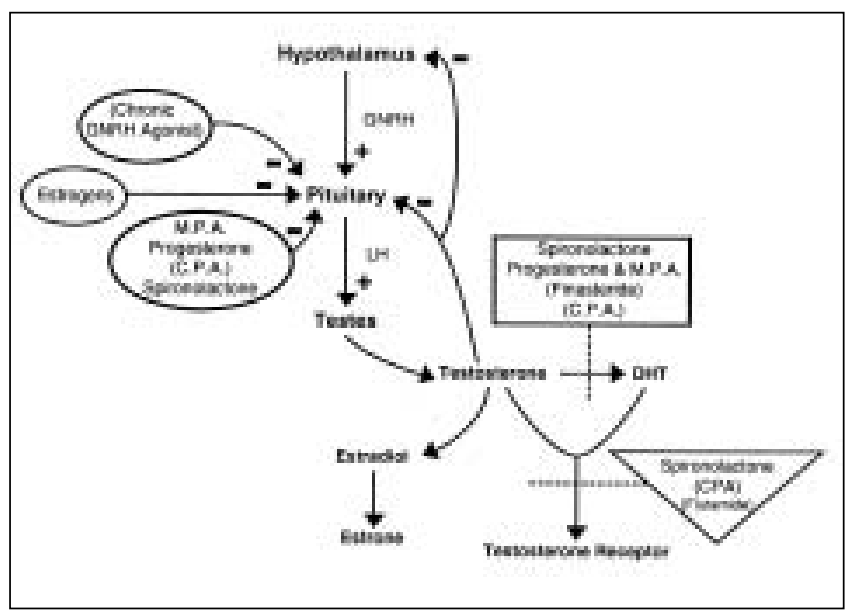

Figure 1) Various methods to achieve a lack of activity of testosterone and dihydrostestosterone. CPA Cyproterone acetate; DHT Dihydrotestosterone; GNRH Gonadotrophic releasing hormone; LH Luteinizing hormone; MPA Medroxyprogesterone acetate

conversion of testosterone to DHT with spironolactone, CPA or finasteride; or directly inhibiting the receptor for testosterone and DHT with spironolactone, CPA or flutamide. Figure 1 clarifies that most drugs have more than one site of action. Estrogen is given primarily for feminization. Clearly, estrogen can also suppress LH, but the dose required for suppression is pharmacological and associated with cardiovascular risk.

\section{MODEL HORMONAL REGIMEN}

The three drugs that were used in the vast majority of 430 patients who attended the Vancouver Hospital Centre for Sexuality, Gender Identity and Reproductive Health, Vancouver, British Columbia from 1986 to 1998 were MPA (10 to $30 \mathrm{mg}$; occasionally, $50 \mathrm{mg}$ was used), spironolactone (200 to $400 \mathrm{mg}$ ), and either conjugated estrogens (CES) (0.625 to $1.25 \mathrm{mg}$ ) or transdermal 17-beta estradiol (50 to $100 \mu \mathrm{g}$ ) daily.

\section{LH SUPPRESSION}

MPA is commonly used to suppress LH and can alone suppress testosterone to castrate levels (2). The addition of a synthetic progestin does lessen the beneficial estrogenic effect of increasing high density lipoprotein (HDL) cholesterol and decreasing low density lipoprotein (LDL) cholesterol, as it does in biological women. The importance of these laboratory findings is not known in the person with 


\section{PERSONAL USE ONIYY DO NOT COPY}

Hormonal treatment of male to female gender identity disorder COPYRIGHT PULSUS GROUP HINComan

GID; however, Grodstein and et al's report (3) on postmenopausal women provides hope in that the cardiovascular clinical outcome was improved with the use of MPA and estrogen over and beyond the outcome when using estrogen alone (3). MPA in dosages of 10 to $30 \mathrm{mg}$ daily, as is needed for LH suppression in GID management, is nonandrogenic. Nortestosterone derivatives that are androgenic are avoided. Micronized progesterone is more expensive but useful for the patient with low HDL cholesterol; any further lowering of HDL cholesterol by MPA is avoided, and the full benefit of estrogen on HDL cholesterol is preserved (4).

The antagonism of remaining testosterone is achieved with spironolactone (200 to $400 \mathrm{mg}$ daily) $(5,6)$. The initial diuretic effect is usually not seen after three to four months, but patients are cautioned not to restrict fluids, and renal function is monitored. Spironolactone's hypotensive effect is an advantage in many cases, but in a small minority of patients, particularly in the leaner and very physically active individual, the hypotensive effects necessitate a change in therapy. CPA is an alternative agent that also acts as a progestin. It inhibits LH production, antagonizes the testosterone receptor, and competes with 5-alpha reductase, but its tendency to cause depression (7) limits its usefulness. A high incidence of depression with its associated increased risk of suicide, for which persons with GID are already at increased risk, is reported by Asscheman et al (7) who routinely use CPA. Flutamide, a direct antagonist of testosterone, is expensive, potentially hepatotoxic and increases testosterone production in the temporarily noncastrated person with GID. Similarly, finasteride, while reducing DHT production, allows the continued action of testosterone.

\section{FEMINIZATION WITH PHYSIOLOGICAL ESTROGEN}

Estrogen is prescribed in doses that would be physiological to the peri- and postmenopausal biological woman; the choices are CES $0.625 \mathrm{mg}$ (occasionally $1.25 \mathrm{mg}$ ) daily, transdermal 17-beta estradiol $50 \mu \mathrm{g}$ (occasionally $100 \mu \mathrm{g}$ ) daily, estropipate $0.625 \mathrm{mg}$ (occasionally $1.25 \mathrm{mg}$ ) daily or micronized estradiol $1 \mathrm{mg}$ (occasionally $2 \mathrm{mg}$ ) daily. These 'physiological' dosages of estrogen are used rather than pharmacological dosages of oral contraceptives, thus reducing the risk of venothromboembolic events (VTE), which is known to be increased about five times by the use of supraphysiological dosages (as in current oral contraceptives) in biological women (8). It is also known that the overall incidence of VTE in persons with GID who use $100 \mu \mathrm{g}$ of oral ethinyl estradiol is about 5.5\% (9). Also, the risk of cardiac events is slightly increased in biological women taking estrogen in oral contraceptive dosages (10). Despite this, other authors still recommend 'initial treatment' consisting of "judicious administration of an estrogen such as ethinyl estradiol $100 \mu \mathrm{g}$ daily, or CES 1.25-2.5 mg daily" (6). Thus, almost four times the usual dosage of estrogen in currently prescribed oral contraceptives ( 20 to $35 \mu$ g ethinyl estradiol) is still being recommended (and this dosage is about five to 10 times more potent than 1.25 or even $2.5 \mathrm{mg}$ of CES).
TABLE 1

Complete and relative contraindications to estrogen

therapy in male to female gender identity disorder

Contraindications

Known coronary artery disease

Thromboembolic disease

Cigarette smoking

Refractory migraine

Hyperprolactinemia

Relative contraindications that should be investigated and treatment individualized

Other cardiac disease

Marked hypertriglyceridemia

Family history of abnormal clotting

History of heavy cigarette use

History of benign intracranial hypertension

Marked obesity and type 2 diabetes

Poorly controlled diabetes

Hepatic dysfunction

Past history of focal migraine

Epilepsy

Cerebral vascular disease

Strong family history of breast cancer

Unfortunately, the safety of 'physiological' estrogen in the person with GID cannot be assumed. Even if testosterone is suppressed, is it possible to extrapolate findings related to postmenopausal women on estrogen replacement therapy (ERT)? Clinical experience suggests that the careful assessment and reduction of other known risk factors of cardiovascular disease allow this regimen to be safe (Table 1), but questions remain. For example, which (if any) of estrogen's presumed overall benefits on cardiovascular health in biological women apply to the person with GID?

\section{ESTROGEN ADMINISTRATION AND CARDIOVASCULAR PROTECTION}

Reduced estrogen production after menopause is associated with less nitric oxide (NO) activity, and thus, endothelialdependent vasodilation is impaired (11); however, it is reversed by exogenous estrogen (12). Research from Australia has shown that in a person with GID who takes either physiological or pharmacological doses of estrogen, $\mathrm{NO}$ activity is increased compared with that in biological men and is similar to that in premenopausal women (13). The Australian researchers used reactive hyperemia to increase blood flow in the brachial artery, a stimulus that is known to trigger NO-dependent vasodilation. Whether this increase in NO activity is due to the decreased degradation of endothelial nitric oxide synthase (NOS-III) or the increased production of NOS-III, as is thought to occur in biological women, is not clear $(14,15)$. Additionally, estrogen may inhibit NO degradation by inhibiting superoxide anion formation or by increasing the level of endogenous free radical scavengers (15). NO from endothelial cells diffuses to 
smooth muscle in the arterial wall, allowing endotheliumdependent vasodilation, and into the arterial lumen where it can prevent the adherence of monocytes and platelets that are involved in the formation of the atherosclerotic lesion $(16,17)$.

Other potential mechanisms by which estrogen exerts cardiovascular protection are worth considering. The Australian group showed a direct vasodilator effect of estrogen in the person with GID that is comparable with the premenopausal woman; the response to nitroglycerin is greater in persons with GID and in women than in men (13). Certainly, estrogen's ability to increase HDL and reduce LDL cholesterol is seen in the person with GID (18). The suppression of smooth muscle cell proliferation is another potential benefit of estrogen (19), as is its antoxidant activity (20), by preventing the LDL cholesterol oxidation involved in atherogenesis. Information on this benefit in the treatment of GID is required, along with information on the estrogenic inhibition of hepatic lipase (21), which reduces the conversion of $\mathrm{HDL}_{2}$, which is cardioprotective, to $\mathrm{HDL}_{3}$ (22). It appears that oral but not transdermal estrogen is associated with a 33\% reduction in hepatic lipase (23). The reduction of lipoprotein (Lp) (a), as is seen with ERT in women (24) and is known to be particularly important for their cardiovascular health (25), has yet to be investigated in persons with GID. In postmenopausal women, the increased activity of the plasminogen activator inhibitor is reversed by giving estrogen (26). In the gender identity disordered person receiving estrogen, the plasminogen activator inhibitor and the plasminogen activator are both decreased (27). Levels of homocysteine that are associated with the incidence of ischemic heart disease and stroke are higher in postmenopausal than in premenopausal women can be reduced by estrogen administration (28). Homocysteine levels in persons with GID treated with estrogen have been shown to be comparable with levels in premenopausal women (29). Regarding the likely role of inflammation in arterial disease, transdermal estradiol has been shown to reduce C-reactive protein concentrations in postmenopausal women; high Creactive protein is associated with having type 2 diabetes (30). C-reactive protein concentrations in persons with GID before and after estrogen therapy have not been investigated.

In the much quoted male 1973 coronary drug research project, when combined with other cardiovascular risk factors and in the presence of unknown testosterone levels, supraphysiological doses of estrogen did hasten cardiac morbidity and mortality (31). On the other hand, low dose estrogen in the context of low androgen activity may well promote cardiovascular health (32).

\section{ESTROGEN ADMINISTRATION AND CARDIOVASCULAR RISK}

Despite the contention that low dose estrogen may actually be beneficial to the cardiovascular system of the person with GID, caution is still needed for the following reasons.
- Questions regarding VTE remain. Even with low doses of estrogen, up until 1996, most investigators felt that VTE was not more frequent in users of ERT than in nonusers. However, three papers in 1996 required that this finding be reconsidered. Although all three studies pointed out that the actual incidence of these phenomena in postmenopausal women taking estrogen was very low, the studies produced relative risk ratios of 3.5 (33), 3.6 (34) and 2.1 (35). Thus, estrogen may be withheld in the transgendered patient if there is a personal or family history of VTE, cancer, marked obesity or a particularly sedentary lifestyle. Previously, transdermal estrogen in postmenopausal women was thought to be safer; however, in their sample, Daly et al (33) did not find any difference between oral or transdermal estrogen. Nevertheless, physicians at the Free University Hospital in Amsterdam, the Netherlands have routinely given their patients with GID transdermal estrogen after 40 years of age once they witnessed a high incidence of VTE from high dose oral formulations (9). After a switch to transdermal (and lower dose) estrogen, the incidence of VTE dropped. The only recommendation on hormonal therapy in the Harry Benjamin Guidelines (36) is to consider using transdermal estrogen for those over 40 years of age. It remains very unclear, however, whether it is the route rather than the lower dose that will afford protection from VTE.

- Reservations about the benefit on lipids remain. The beneficial increase in HDL cholesterol is not seen if transdermal estrogen is used. Hypertriglyceridemia may follow oral estrogen therapy, but the risks from estrogen-induced hypertriglyceridemia (as opposed to endogenous hypertriglyceridemia) are unclear (37).

- The recently completed large randomized trial using continuous combined CES and MPA or placebo on 2700 postmenopausal women with known pre-existing coronary artery disease showed no overall effect of the intervention for subsequent coronary events. However, the intervention group had significantly more events in the first year of the trial and fewer during years 4 and 5 (38). Again, although these studies are in biological women, known coronary artery disease in the person with GID should probably be considered a contraindication to commencing any estrogen therapy. 


\section{PERSONAL USE ONLY DO NOT COPY \\ Hormonal treatment of male to female gender identity disorder ADDITIONAL POTENTIAL RISKS \\ OF ESTROGEN ADMINISTRATION \\ Further potential risks of estrogen administration are as fol- \\ TABLE 2 \\ Follow-up in patients with male to female gender identity disorder seen at the Vancouver Hospital Centre for Sexuality and Gender Identity and Reproductive Health from 1986 to 1998 *} lows.

- Regarding the risk of breast cancer, the modest increase shown in biological women after five years of postmenopausal therapy (39) necessitates caution with long term estrogen therapy for GID.

- Decreased bone density may theoretically follow the removal of testosterone, despite the presence of estrogen and progesterone. This is a major reason for the continuation of sex hormone treatment after reassignment surgery. Many patients begin with low bone density that is possibly related to delayed puberty from the stress of the gender dysphoric condition or to previous cigarette use and poor nutrition. All pre- and postoperative patients are advised to take supplemental calcium.

- The elevation of prolactin level is well documented after pharmacological estrogen usage $(8,40)$ but is rarely problematic with a physiological dose.

\section{INDIVIDUALIZATION OF ESTROGEN ADMINISTRATION}

Individualization of physiological estrogen treatment takes into account pre-existing lipid levels; a history of smoking or VTE; a family history of diabetes, VTE or breast cancer; or early myocardial infarction. All patients are encouraged to exercise, cease smoking, and address abnormalities in lipids and glucose tolerance. Measuring estradiol levels is of little help given that CES contains little estradiol, and estradiol levels are unexpectedly low in biological women who use transdermal estradiol, despite clinical benefits; the reasons for the relatively low blood level are unclear. Management of the person with GID with known ischemic heart disease is unclear. The relevant data are lacking. Previous theoretical arguments favour prescribing physiological oral estrogen, but the results from recent studies of secondary prevention of cardiac events in postmenopausal women receiving estrogen and progesterone indicate continued caution $(38,41)$.

Table 1 shows current views on complete and relative contraindications to estrogen therapy.

\section{OUTCOME OF LOW DOSE ESTROGEN ADMINISTRATION, TESTOSTERONE SUPPRESSION AND ANTAGONISM}

Table 2 shows a low incidence of cardiovascular events and hyperprolactinemia for the 430 patients in the authors' study over the 12-year period, confirming the safety of physiological estrogen administration in the presence of androgen suppression.

\begin{tabular}{lc}
\hline & $\begin{array}{c}\text { Number } \\
\text { Follow-up status }\end{array}$ \\
In active follow-up & 313 \\
Seen for initial endocrine assessment & 430 \\
No longer wished follow-up after sex reassignment surgery & 16 \\
Known to have moved out of British Columbia & 35 \\
Before surgery, preferred follow-up with family physician & 9 \\
Lost to follow-up (did not show or not return phone calls & \\
and letters) & 19 \\
Lost to follow-up (phone discontinued or no forwarding & \\
address) & 39 \\
Prescribed spironolactone MPA physiological & 383 \\
$\quad$ estrogen & \\
Number in active follow-up on spironolactone, MPA, & 279 \\
physiological estrogen & 2 \\
Deceased (suicide) & \\
Complications & 3 \\
Venothromboembolic events & 0 \\
Myocardial infarction & 1 \\
Hyperprolactinemia (more than two times the upper limit) & 0 \\
Liver abnormalities related to hormonal use & 0 \\
Carbohydrate intolerance & 11 \\
Worsening of lipid profile requiring medication & 7.1 \\
\hline Mean duration of hormone follow-up (in years ) & \\
*Three persons seen at the clinic experienced myocardial infarctions but \\
had only received spironolactone due to their very high risk of myocar- \\
dial infarction. One other person experienced a venothromboembolic \\
event but had disregarded the clinic's advice and obtained 5 mg conju- \\
gated equine estrogens daily from elsewhere. MPA Medroxyprogesterone \\
acetate
\end{tabular}

The rate of feminization varies. The breast, nipple and areola develop just as during female puberty, taking usually three to six years. Body weight and genetic predisposition affect the final breast size. Body hair becomes finer, sparse and is often almost completely lost in one to three years; a female pubic hairline continues. Temporal and scalp hair fills in to varying degrees, depending on the duration of balding and loss of hair follicles. A female contour to the thighs, buttocks, cheeks and abdomen follows breast development. Beard loss varies, with the upper lip and chin being most resistant to hair loss and often requiring electrolysis (this is a similar outcome to that of clinics using pharmacological doses of estrogen).

Poor testosterone suppression (to the lower end of the male range) with the expected inadequate feminization, despite maximum doses of spironolactone ( $500 \mathrm{mg}$ ), MPA $(50 \mathrm{mg})$ and CES $(1.25 \mathrm{mg})$, were noted in five patients (Table 3). The addition of CPA was associated with further testosterone suppression in four patients, but its use was discontinued in one patient due to the exacerbation of depression. 
TABLE 3

Outcome of treatment with spironolactone, medroxyprogesterone acetate and physiological estrogen before sex reassignment surgery in patients seen at the Vancouver Hospital Centre for Sexuality, Gender Identity and Reproductive Health from 1986 to 1998

\begin{tabular}{lc}
\hline Outcome & $\begin{array}{c}\text { Number } \\
\text { of patients }\end{array}$ \\
\hline In active follow-up & 279 \\
Testosterone suppressed to less than $5.0 \mathrm{nmol} / \mathrm{L}$ & 201 \\
Testosterone suppressed to between 5.0 and $9.0 \mathrm{nmol} / \mathrm{L}$ & 73 \\
Testosterone suppressed to low male range & 5 \\
Incomplete feminization of breasts (Tanner III or less) & 13 \\
$\quad$ at five years &
\end{tabular}

For the patients who were unable to be prescribed estrogen due to known coronary artery disease at presentation (nine patients) and due to inability to discontinue cigarette smoking (25 patients), breast development was only to Tanner III level in 10 patients (Tanner IV and V levels in the remaining patients). This occurred despite the suppression of testosterone levels to less than $5.0 \mathrm{nmol} / \mathrm{L}$.

Routine follow-up includes a systems enquiry; a full physical examination; and measurement of HDL and LDL cholesterol, prolactin, testosterone, and fasting blood glucose, urea and creatinine levels. Bone density and other tests are ordered as is necessary.

The safety and efficacy of the described hormonal regimen have been clarified. To assess patient acceptance, we reviewed the charts of our inactive patients (Table 1 ). No patients are known to have left the clinic due to the clinic's views on hormonal regimens. However, some patients who preferred follow-up by family physicians or other specialists may have found physicians who were comfortable with prescribing pharmacological doses of estrogen. Physicians at the clinic have been interested in meeting GID patients who have received pharmacological doses of estrogen (eg, $100 \mu \mathrm{g}$ of ethinyl estradiol) from elsewhere who are not feminizing either quickly or significantly - the reasons offered in the literature for such prescribing (6).

\section{HORMONAL REGIMEN AFTER SRS}

The withdrawal of estrogen will not cause a reversal of the secondary female sexual characteristics but will increase the risk of osteoporosis. Patients, therefore, continue with the equivalent of CES $(0.625 \mathrm{mg})$ or if estrogen is contraindicated because of a risk of VTE or cardiac complication or if there is a high familial risk of breast cancer, then a bisphosphanate and/or the continuation of progesterone (42) would be considered and guided by bone density studies. Referring again to the development of SERMS, an exciting possibility for future treatment may involve feminizing estrogen for a limited time frame (eg, five to 10 years), followed by a tissuespecific estrogen to maintain the benefit on vascular and bone health but without deleterious action on thrombogenesis or on the recently acquired breast tissue. Spironolactone is continued only if there is persistent beard growth and electrolysis is not possible.

\section{CONCLUSIONS}

Based on present knowledge, the hormonal treatment of choice for the male to female GID state includes MPA or micronized progesterone to suppress $\mathrm{LH}$, spironolactone to antagonize testosterone action and a physiological dose of estrogen to feminize patients. While attempting to achieve as much feminization as possible and the loss of some male attributes, the overriding guiding principle remains to do no harm. Any apparent benefit of postmenopausal estrogen replacement in biological women cannot necessarily be extrapolated to the GID population. The theoretical and preliminary clinical evidence of cardiovascular benefit from estrogen has been discussed. Morbidity data from the 279 patients in active follow-up receiving physiological estrogen, along with testosterone suppression and antagonism for GID, suggest that this regimen is indeed safe. Long term follow-up from all clinics is needed, particularly in view of current research on the mechanisms of endogenous and exogenous estrogen in biological women and the development of SERMS

ACKNOWLEDGEMENTS: The author thanks Dr Peter Rees for editorial assistance, Mrs Maureen Piper for her secretarial expertise and $\mathrm{Mr}$ Blaine Beemer for the analysis of inactive patients.

\section{REFERENCES}

1. Green R. Mythological, historical, and cross-cultural aspects of GID. In: Denny D, ed. Current Concepts in Transgender Identity, 1st edn. New York: Garland Publishing Inc, 1998:3-14 .

2. Basson R. Sexuality and Parkinson's disease. Parkinsonism \& Related Disorders 1996;2:177-85.

3. Grodstein F, Stampfer M, Manson J, Colditz G. Postmenopausal estrogen and progestin use and the risk of cardiovascular disease. N Engl J Med 1996;335:453-62.

4. The Writing Group for the PEPI Trial. Effects of estrogen or estrogen/progestin regimes on heart disease risk factors in postmenopausal women. The Postmenopausal Estrogen/Progestin Interventions (PEPI) trial. JAMA 1995;273:199-278.

5. Prior JC, Vigna YM, Watson D. Spironolactone with physiological female steroids for presurgical therapy of male-tofemale transsexualism Arch Sex Behav 1989;18:49-57.

6. Futterweit W. Endocrine therapy of transsexualism and potential complications of long-term treatment. Arch Sex Behav 1998;27:209-26.

7. Asscheman H, Gooren LJ, Ekland PL. Mortality and morbidity in transsexual patients with cross-gender hormone treatment. Metabolism 1989;38:869-73.

8. Poulter NR. World Health Organization collaborative study of cardiovascular disease and steroid hormone contraceptives. Venous thromboembolic disease and combined oral contraceptives: Results of international multi centre case control study. Lancet 1995;346:1575-82.

9. van Kesteren PJ, Asscheman H, Megens JA, Gooren LJ. Mortality and morbidity in transsexual subjects treated with cross sex hormones. J Clin Endocrinol 1997;47:337-42.

10. Lewis MA, Spitzer WO, Heinemann LAJ, MacRae KD, Thorogood M. Third generation oral contraceptives and risk of 


\section{PERSONAR USE ONIY - DO NOT COPY \\ on: An international case control study.

myocardial infarction: A

11. Cicinelli E, Ignarro L, Lograno M, Matteo G, Falco N, Schonauer LM. Acute effects of transdermal estradiol administration on plasma levels of nitric oxide in postmenopausal women. Fertil Steril 1997;67:63-6.

12. Ramsay B, Johnson MR, Leone AN, Steer PJ. The effect of exogenous estrogen on nitric oxide production in women: the placebo control cross over study. Br J Obstet Gynecol 1995;102:417-19.

13. New G, Timmins SK, Duffy S, et al. Long term estrogen therapy improves vascular function in male to female transsexuals. J Am Coll Cardio 1997;29:1437-44.

14. Kauser K, Rubanyi GB. Potential cellular signaling mechanisms mediating up regulation of endothelial nitric oxide production by estrogen. J Vasc Res 1997;34:229-36.

15. Losordo DW, Kearney M, Kim EM, Jekanowski J, Isner JM. Variable expression of the estrogen receptor in the normal and the atherosclerotic coronary arteries of premenopausal women. Circulation 1994;89:1501-10.

16. Palmer RMJ, Ferridge AG, Moncada S. Nitric oxide release accounts for the biological activity of endothelium-derived relaxing factor. Nature 1987;327:524-26.

17. Bath PMW, Hassall DG, Gladwin AM, Palmer RMJ, Martin FJ. Nitric oxide and prostacyclin: divergence of inhibitory effects of monocyte chemotaxis and adhesion to endothelium in vitro. Arterioscler Thromb 1991;11:254-6.

18. Damewood MD, Bellantoni JJ, Bachorik PS et al. Exogenous estrogen effect on lipid/lipoprotein cholesterol in transsexual males. J Endocrinol Invest 1989;12:449-54.

19. Orino A, Inou EF, Ouchi Y, Orino H. Vascular smooth muscle cell possess estrogen receptor and respond to estrogen. Ann N Y Acad Sci 1991;748:592-4.

20. Sack MN, Rader DJ, Cannon RO 3rd. Estrogen and inhibition of oxidation of low-density lipoproteins in postmenopausal women. Lancet 1994;343:269-70.

21. Applebaum-Bowden D, McClean P, Steinmetz A, Fontana D, Matthys C. Lipoprotein, apolipoprotein and lipolytic enzyme changes following estrogen administration in postmenopausal women. J Lipid Res 1989;10:1895-906.

22. Miller NE. Association of high density lipoprotein subclasses and apolipoproteins with ischemic heart disease and coronary atherosclerosis. Am Heart J 1987;113:589-97.

23. Basdevant A, deLignieres B, Simon P, Blache D, Ponsin G, Guy-Grand B. Hepatic lipase activity during oral and parenteral $17 \mathrm{~b}$ estradiol replacement therapy: high density lipoprotein increase may not be antiatherogenic. Fertil Steril 1991;55:112-7.

24. Mosca L, Bowlin S, Davidson L, Jenkins P, Pearson TA. Estrogen replacement therapy and lipoprotein (a). Circulation 1991;84(Suppl 2):2169. (Abst)

25. Dahlen GH, Guyton JR, Attar M, Farmer JA, Kautz JA, Getts AM. Association of levels of lipoprotein Lp(a) plasma lipids and other lipoproteins with coronary artery disease documented by angiography. Circulation 1986;74:758-65.

26. Koh KK, Mincemoyer R, Bui MN, et al. Effects of hormone

replacement therapy on fibrinolysis in postmenopausal women. N Engl J Med 1997;336:683-90.

27. Van Kesteran PJ, Kooistra T, Lansink M. The effects of sex steroids on plasma levels of marker proteins of endothelial cell functioning. Thromb Haemost 1998;79:1029-33.

28. Vandenmooren MJ, Walters NG, Blan HJ. Hormone replacement therapy may reduce high serum homocysteine in postmenopausal women. Eur J Clin Invest 1991;24:733-6.

29. Giltay EJ, Hoogeveen EK, Elbers JMH, Gooren LJG, Asscheman H, Stehouwer CDA. Effects of sex steroids on plasma total homocysteine levels; a study in transsexual males and females. J Clin Endocrinol Metab 1998;83:550-3.

30. Sattar N, Perra M, Small M, Lumsden M. Hormonal replacement therapy and sensitive $\mathrm{C}$-reactive protein concentration in women with Type II diabetes. Lancet 1999;354:487-8

31. The coronary drug research group: The coronary drug project. JAMA 1973;76:652-7.

32. Yeung AC. Estrogen for men: Reversal of cardiovascular misfortune? J Am Coll Cardiol 1997;29:1445-6.

33. Daly E, Vessey M, Horkins M, Carson J. Risk of venous thrombo embolism and usage of hormone replacement therapy. Lancet. 1996;348:977-80.

34. Jick H, Derby L, Myers MW Vasilakis C, Newton KM. Risk of hospital admission for idiopathic venous thrombo embolism in women. Lancet 1996;348:981-3.

35. Grodstein, Stampfer M, Goldhaber S. Prospective study of exogenous hormones and risk of pulmonary embolism in women. Lancet 1996;348:983-7.

36. The Harry Benjamin International Gender2Dysphoria Association. <http://www.hbigda.org> (Version current at April 11, 2001)

37. Knopp RH, Zhu X, Bonet B, Bagatell C. Effects of sex steroid hormones on lipoproteins, clotting and the arterial wall. Semin Reprod Endocrinol 1996;14:15-27.

38. Hulley S, Grady D, Bush T. Randomized trial of estrogen plus progestin for secondary prevention of coronary heart disease in postmenopausal women. Heart and Estrogen/Progestin Replacement Study (HERS) research group. JAMA 1998;280:605-13

39. Collaborative Group on Hormonal Factors in Breast Cancer. Breast cancer and hormonal replacement therapy: Collaborative reanalysis of data from 51 epidemiological studies of 52, 705 women with breast cancer and 108, 411 without breast cancer. Lancet 1997;350:1047-59.

40. Covacs K, Stetaneanu L, Ezzat SD, Smyth HS. Prolactin-producing pituitary adenoma in a male-to-female transsexual patient with protracted estrogen administration: A morphological study. Arch Pathol Lab Med 1994;118:562-65.

41. Herrington DM, Reboussin DM, Brosnihan KB, et al. Effects of estrogen replacement on the progression of coronary artery atherosclerosis. N Engl J Med 2000;343:522-9.

42. Prior JC, Vigna YM, Barr SI, Rexworthy C. Cyclic medroxy progesterone treatment increases bone density: A controlled trial in active women with menstrual cycle disturbances. Am J Med 1994;96:521-30. 